\title{
Juegos populares y tradicionales, ocio y diferencia colonial*
}

\author{
José Fernando Tabares Fernández**
}

\begin{abstract}
Resumen: El presente artículo se inscribe en el marco de la perspectiva de la modernidad/colonialidad, que busca aportar a la construcción de un marco de análisis para el ocio en las sociedades periféricas. Desarrolla la categoría "diferencia colonial”, para dar cuenta de la forma como el ocio es configurado en este espacio particular, a partir de procesos de tensión entre las historias locales y los diseños globales. Propone una mirada que busca aportar a los necesarios procesos de reflexión y problematización del ocio, en sociedades que por su configuración en el sistema-mundo moderno/colonial, han sido ubicadas en condiciones de subalternidad e inferioridad.
\end{abstract}

Palabras clave: Ocio, modernidad/colonialidad, diferencia colonial, juegos populares y tradicionales.

\section{Folk and traditional games, entertainment and colonial difference}

\begin{abstract}
This paper installs itself in the coloniality/modernity perspective, which intends to contribute to the building up of an analysis framework for leisure in peripherical societies. It develops the "colonial difference" category, in order to give account of the way leisure is configured in this special field, emerging from tensional processes between local stories and global designs. It proposes a view that seeks to contribute to the necessary analysis and problematization of leisure, in societies which, due to their configuration in the modern/colonial world-system, have been placed in subaltern and inferiority conditions.

Key words: Leisure, modernity/coloniality, colonial difference, traditional and popular games.
\end{abstract}

\section{Jogos populares tradicionais, lazer e diferença colonial}

Resumo: Este artigo se inscreve no marco da perspectiva da modernidade / colonialidade, que visa contribuir para a construção de um quadro de analise para

\footnotetext{
* Este artículo hace parte del trabajo de tesis doctoral Conocimiento y colonialidad en los estudios de ocio, recreación y tiempo libre en Colombia, adelantado por el autor para acceder al título de doctor en ocio y potencial humano de la Universidad de Deusto de BilbaoEspaña. El objeto de este trabajo, es la problematización de los marcos de referencia tradicionales para el estudios de ocio y la propuesta de marcos de referencia otros, más amplios, donde sea posible la relación de tensión entre distintas perspectivas -las globales y las locales-, todas en igualdad de condiciones.

** Instituto de Deportes y Recreación de Medellín, Colombia. E-mail: jfernando37@hotmail.com.
} 
o lazer nas sociedades periféricas. Desenvolve a categoria diferença colonial para dar conta da forma como o lazer é definido neste espaço particular, a partir dos processos de tensão entre as histórias locais e os projetos globais. Propõe um olhar que busca contribuir para os necessários processos de reflexão e problematização do lazer, em sociedades que por sua configuração no sistema-mundo moderno/ colonial, foram colocadas em uma posição de subordinação e de inferioridade.

Palavras-chave: Lazer; Modernidade/Colonialidade; Diferença colonial; Jogos populares tradicionais.

Recibido: 30.04 .2010

Aceptado: 30.06.2010

Este artículo, hace parte de un proceso de reflexión del ocio desde la perspectiva de la modernidad/colonialidad que de acuerdo con Escobar (2005: 70-71), se define a partir de cinco operaciones, que lo diferencian de las llamadas teorías tradicionales de la modernidad. La primera hace referencia al cambio del marco histórico tradicional, que ubicaba la historia de la periferia en el siglo XVIII. En este sentido se retoma la llegada de los ibéricos a América y el control del Atlántico Norte en 1492. La segunda operación, tiene que ver con la explicitación del colonialismo como un importante aspecto, que hace parte de la modernidad y por tanto de las formas de intervenir la periferia. Un tercer aspecto se refiere al cambio de la perspectiva intraeuropea, por otra mundial, frente al análisis de la modernidad. La dominación en espacios extraeuropeos y los consiguientes procesos de subalternización de conocimientos y culturas como un elemento constitutivo de la modernidad, como cuarta operación. Por último, la problematización del eurocentrismo, como la forma del conocimiento de la modernidad/colonialidad, hegemónica y universal, fruto de la ubicación central de Europa.

Busca fundamentalmente, hacer un recorrido por los procesos de instauración de un modelo global en una historia local, bajo situaciones de tensión, identificando el proceso bajo el que se configuró una nueva realidad en espacios del mundo con unas formas de vida, de producción, de sociabilidad, juegos, fiestas y diversiones, que se correspondían con lo local, y que fueron y siguen siendo intervenidas desde un imaginario que los subalterniza y los intervine para su transformación o desaparición.

Se busca desde la diferencia colonial ${ }^{1}$, dar cuenta del proceso que se vivió en torno a su intervención, pero también, arrojar luces de cómo se

\footnotetext{
${ }^{1}$ La diferencia colonial es el espacio en el que se articula la colonialidad del poder. Es también el espacio en el que se está verificando la restitución del conocimiento subalterno y está emergiendo el pensamiento fronterizo. La diferencia colonial es el espacio en el que las historias locales que están inventando y haciendo reales los diseños globales se encuentran con aquellas historias locales que los reciben; es el espacio en el que los diseños globales tienen que adaptarse e integrarse o en el que son adoptados, rechazados o ignorados. La diferencia colonial es, finalmente, la localización tanto física como imaginaria desde la que
} 
configuraron realidades, que hasta el día de hoy promueven referentes para diferenciar las distintas prácticas, en una jerarquía de las formas superiores, presentadas como las únicas a las que se pueden catalogar como tal, y de otras, ubicadas en peldaños inferiores, con denominaciones que las refieren en condición de subalternidad.

Es decir, desde la perspectiva de la diferencia colonial, con la asignación de valores, de acuerdo con las razas, las prácticas de ocio y la posibilidad de unas ciertas vivencias, son asignadas a grupos de personas, ubicadas en unos ciertos espacios, propuestas además como referentes de civilización y sensibilidad, y otras, asignadas a los habitantes de la periferia a los que se les atribuyen de igual manera, unos valores que los subvaloran bajo denominaciones tales como populares, tradicionales o autóctonos en unos casos, o como vagancia y ociosidad cuando no se corresponden con las necesidades de disciplinamiento.

Dicho en otras palabras, de la misma manera que la diferencia colonial subalternizó formas de conocer y pensar, formas de producción, escrituras no alfabéticas, etc., también lo hizo con las prácticas de ocio y las formas de vida que las sustentaban. Que luego en la segunda modernidad (para la perspectiva histórica de la modernidad/colonialidad, la modernidad inicia en XV y no en el siglo XVIII -segunda modernidad-como se explica tradicionalmente) y posteriormente en la época del desarrollo, sirvieron como asiento para nuevas clasificaciones, que igualmente justificaron los procesos de intervención para llevar a los seres humanos desde unos estados anteriores hacia unos presentes, según los instauradores, mejores para la existencia humana.

Bajo la operación hecha en la segunda modernidad, con dos regularidades fundamentales, lo temporal y lo espacial, las prácticas de ocio propias de lo local fueron ubicadas desde la primera como prácticas del pasado, y desde la segunda, en las exterioridades de la modernidad, como lugares donde las prácticas que se desarrollaban -tradicionales- no se correspondían con las realizadas en los espacios centrales -modernas-. Por ello se retoman las categorías de ocio y juegos populares y tradicionales, para explicitar las dos grandes perspectivas desde las cuales puede apreciarse el objeto de interés, tanto en el centro como en la periferia.

Como consecuencia de lo anterior, hay otro asunto que debe quedar claro, y es el que de acuerdo con Kelly (2000:57), tiene que ver con la posición de que el cambio más importante en los estudios de ocio en la última década, es la consideración del ocio como un fenómeno "refutable”. Es decir, el ocio como asunto que no corresponde sólo al tipo de prácticas,

la colonialidad del poder está operando a partir de la confrontación entre dos tipos de historias locales que se desarrollan en distintos espacios y tiempos a lo largo del planeta. Si la cosmología occidental constituye un punto de referencia históricamente inevitable, las confrontaciones múltiples entre estos dos tipos de historias locales desafían las dicotomías (Mignolo 2007: 8). 
discursos, imaginarios, espacios y artefactos propuestos desde los discursos construidos en las sociedades centrales, sino que se corresponde con las características sociales, culturales, políticas, económicas, etc., de las diferentes sociedades del mundo. Esta afirmación, se retoma no sólo para las miradas actuales del ocio en las sociedades de la periferia, sino además para las miradas retrospectivas, que permiten, de alguna manera, leer y problematizar las formas como han sido abordados los análisis históricos del ocio en sociedades expuestas a procesos de intervención y transformación. En palabras de Kelly (2000:57):

“... el ocio como algo socialmente imbricado en lugar de cómo algo separado o especial; el ocio como aspecto culturalmente situado, el ocio como aspecto político y el ocio como aspecto basado en los esquemas de producción y distribución de una economía mundial capitalista. La naturaleza refutable del ocio suscita, asimismo, los antiguos aspectos sociológicos de género y clase social y los asuntos culturales de raza y etnia”.

Se asume, que este campo de análisis no es entendido como un ideal filosófico, ni tampoco como un determinado grupo de prácticas propias de ninguna sociedad en particular. Con este autor, comprendemos que el ocio es un complejo campo de prácticas atravesado por elementos de tipo social, político, económico, cultural, etc. Así entonces, la diferencia colonial aparece como un mediador idóneo para comprender la presencia de múltiples expresiones, ninguna subalternizada, y ninguna por encima de las otras. Prácticas que se viven en lo local, unas correspondientes a los diseños globales y otras insertas en las historias locales, en situación, estas últimas, de permanente tensión entre las propias y las foráneas, posibilitando espacios para la participación, el empoderamiento y la identidad.

El marco de referencia desde los espacios de la periferia, al contrario de los del centro, debe tener la capacidad de posibilitar la visibilidad de todos en igualdad de condiciones.

\section{Los juegos populares y tradicionales: la cara de las historias locales}

“En el momento del descubrimiento de América la sociedad española y la mayor parte de las que habitaban aquellas tierras estaban bien estratificadas. Hacía tiempo que sus individuos tenían asignada una

función precisa dentro del sistema. El poder lo presidía todo y todo quedaba supeditado a sus intereses”.

"Cuando el europeo se encara con cualquier pueblo indio, el choque cultural esta garantizado. El conquistador impondrá sus formas de vida y también lo hará en lo lúdico, por lo que el mundo indígena de 
la diversión, ira desapareciendo paulatinamente siendo substitutito, casi en su totalidad, por el que traen los recién llegados”

López Cantos 1992: 15-16.

La ubicación del origen de los patrones de diferenciación de la población de la periferia en la primera modernidad, es decir la llegada de los Ibéricos a América, marca la diferencia colonial, que justificará en adelante las formas como se comprenden las realidades locales.

Un elemento que se quiere explicitar sobre los juegos populares y tradicionales, tiene que ver, a diferencia del ocio como diseño global, con la referencia a un lugar especifico. Es decir, la referencia al ocio, se relaciona con un cierto tipo de prácticas y motivaciones que se supone posible leer de la misma manera, en cualquier lugar del mundo. Al contrario, el juego popular y tradicional, hace referencia a un lugar, donde las tensiones entre unas y otras, producen complejas realidades.

En el marco de las diferencias coloniales, el ocio, que actúa como diseño global, corresponde a enunciaciones sin lugar específico y sin tiempo, que lo asumen como espacio que en diferentes partes del mundo, caracteriza un cierto tipo de población, la civilizada. Por el contrario, los juegos populares y tradicionales siempre hablarán de lugares concretos, de dinámicas complejas, de orígenes múltiples, de configuraciones y reconfiguraciones, más acordes con la apuesta de este trabajo por la diversidad.

\section{Para Gomes (2003:59)}

... aunque para la sociología sea una ocurrencia de las sociedades industriales, para la etnología "el problema del ocio" siempre existió. La producción resalta que, para los etnólogos, en las llamadas sociedades primitivas la vida se divide en tres partes: satisfacción de las necesidades elementales, como alimentación y reposo; ocupaciones ligadas a la subsistencia, sobre todo a la agricultura; y actividades lúdicas, como por ejemplo los juegos, las festividades y las danzas.

En este sentido y bajo la línea de este trabajo, la autora se cuestiona, sobre la necesidad de volver la mirada sobre el periodo anterior a la modernidad (es decir, la primera modernidad, bajo la perspectiva de la moderni$\mathrm{dad} /$ colonialidad) y se pregunta sobre la pertinencia o no de utilizar la palabra ocio. Para ella, otros referentes tales como los divertimientos y las actividades lúdicas, serían más pertinentes para contextos como los de la periferia, que es desde donde ella habla.

En esta dirección plantea: "Las manifestaciones culturales consideradas corrientemente lúdicas -tales como los juegos, diversiones, danzas, dramatizaciones- son construidas socialmente por la humanidad, constitu- 
yen patrimonio cultural y reflejan los valores, reglas, tradiciones y costumbres de un determinados grupo. Por esa razón, constituyen un determinado tipo de manifestación cultural siempre presente en nuestra sociedad" (Gomes: 60).

Ante la propuesta de la autora de considerar las llamadas actividades lúdicas, de las denominadas por ella, sociedades tradicionales, la diferencia colonial hace visible que la denominación esconde no sólo una definición, sino la manifestación de una diferenciación que ubica a una por encima de otras. El ocio como referencia de unas prácticas dadas, y las actividades lúdicas, la cultura popular o los juegos populares y tradicionales como referencia de las otras, no son más que el reflejo de la diferenciación de unas prácticas y unos complejos constructos de un mismo fenómeno, que de la mano de los valores asignados desde la diferencia colonial, posicionan unas como las características del modelo civilizador, hacia donde debería avanzar la humanidad entera, y otras propias de las historias locales, ubicadas de un lado, en el pasado, y del otro, en la periferia. Por ello es tan importante, su referencia a Werneck (2003), para hacer visible el hecho de que el ocio es una dimensión de la cultura constituida conforme a las peculiaridades del contexto, "lugar", bien sea del centro o de la periferia. En este sentido afirma Gomes (2003:60): "tratar las manifestaciones culturales de las llamadas sociedades “primitivas” o "tradicionales” como si fueran el ocio de estos grupos encierra puntos oscuros, pues la dinámica social de estas sigue, generalmente, una lógica distinta de aquella verificada en los centros urbanos e industrializados”.

Ante el llamado de Gomes (2003:61), sobre la necesidad de tener en cuenta tanto el ocio griego, como el pan y circo romano, para lograr entender el ocio en estos contextos de la periferia, la diferencia colonial, hace visible la necesidad de entender la historia no tanto para concluir con una definición, con carácter universal, sino con un marco en el que quepan todas, sin la referencia a lo tradicional o primitivo, pues es precisamente en este campo, que actúa la maquinaria de la diferenciación y la subalternización. Desde el enfoque de la modernidad/colonialidad, hablar desde la diferencia colonial, es hacerlo desde estos espacios, que la colonialidad del poder, conformó en la configuración del sistema-mundo moderno/colonial. La restitución del derecho que tienen todas las expresiones, de todos los grupos humanos, es el objetivo que se propone desde este espacio.

En este sentido, se resalta la importancia de hacer visibles los discursos que funcionan sobre el tema. Visibilizar sus orígenes y ubicaciones, posibilitará sin duda, entenderlo mejor y sobre todo, asumir la responsabilidad como académicos de la periferia, de avanzar en la construcción de marcos referenciales otros, que por lo menos superen las miradas hegemónicas de los tradicionales marcos.

Quizás parezca paradójico que la diferencia colonial siga operando en las regiones de la periferia, y que las expresiones propias del ámbito del 
juego, las diversiones, las fiestas, etc., sean puestas en un lugar secundario, sin apenas intentos por propuestas para su recuperación y promoción. Tal vez, porque desde su perspectiva temporal, la modernidad/colonialidad, las ubicó en el pasado o quizás porque la perspectiva espacial, las ubicó en espacios denominados emergentes, subdesarrollados, donde la labor de políticos e intelectuales sea precisamente la de asumir este estatus, abandonando lo propio y apropiándose de aquello que los ubica en estados actuales del sistema mundo moderno, negando la diversidad en el campo de las expresiones lúdicas, para en cambio, instaurar las propias del diseño global.

Y se plantea la paradoja, pues mientras en la región no se asumen acciones decididas, en Europa, se preguntan por los juegos y deportes tradicionales en el siglo XXI (Asociación Europea de Juegos y deportes tradicionales, 1999), proponiendo acciones para su rescate y promoción y haciendo visible el valor de lo local y la identidad. La pregunta que se propone en este momento sería entonces: ¿Qué sucede para que en regiones como Europa, se promueva el rescate y promoción de los juegos populares y tradicionales, mientras en América Latina no se desarrollen acciones ante un ámbito tan vital para, ya no el rescate, sino la visibilización y reconocimiento de las prácticas de los diferentes grupos que configuran estas sociedades interculturales?

El llamado es por el rescate de las historias locales, que desde diferentes países se deben adelantar. En esta dirección, trabajos realizados en países como México, por Viqueira (1995); España, por López (1996); Chile, por Araya (1999) y Purcell (2000), Colombia, por Gómez (2006), dan cuenta de las situaciones vividas en la instauración del diseño global sobre las historias locales y sus implicaciones sobre las expresiones de la cultura popular y del ámbito del ocio específicamente.

Importante pues el llamado de Gomes (2007), sobre algunos aspectos poco tratados en los estudios de ocio en América Latina. De la propuesta que surja para potenciar reflexiones y propuestas, depende que en el campo particular de los estudios de ocio en la región, privilegien los procesos por indagar sobre las formas de instauración como un único modelo, el ocio como diseño global, o por el contrario, reconocer el campo del ocio desde la diversidad, donde las expresiones occidentales aparecen como otras más en el amplio espectro del ámbito del ocio.

Siguiendo la línea de Gomes (2003), de hacer visibles los aspectos históricos, pero ya no sólo desde las necesarias reflexiones para la construcción de un concepto que pueda aglutinar en una sola noción todas las expresiones de lo lúdico, sino sobre todo sus implicaciones en las configuraciones de las realidades locales en una clasificación de los seres humanos, que sirvió como soporte para todos los demás modelos del proceso civilizador. De esta manera y para efectos de hacer visible la diferencia colonial, se propone un recorrido intentando identificar aspectos que hagan evidente esta situación. 
Para este cometido se retoma el planteamiento de Díaz (2008), quien para efectos de dar cuenta de la biopolítica en Colombia, propone tres grandes momentos históricos, con tres registros claves de la modernidad en la Colombia del siglo XX: el capital, el Estado y la ciencia, que a su vez se corresponden con tres estrategias: la estrategia racial, la estrategia educalizadora y la estrategia del desarrollo.

Tres estrategias que permiten develar las formas como primero los colonizadores y luego las clases dominantes de estos territorios construyeron estrategias para el control y transformación de las formas de vida locales, prohibiendo y controlando aquellas expresiones que no se correspondían con el interés de implementar las regularidades del nuevo diseño Global, y que muestran las condiciones bajo las cuales se configuran las expresiones del ocio, como símbolo de distinción, que permitieron la consolidación del dominio y subalternización de los habitantes no ilustrados o como prácticas reprochables que debían ser combatidas hasta hacerlas desaparecer.

De esta manera, historias locales y diseños globales se proponen como referentes para indagar sobre las condiciones que posibilitaron el desarrollo del ocio en las sociedades de la periferia. Los discursos, los imaginarios y las prácticas que en este escenario se generaron, intentando hacer visible, no sólo aspectos que dan cuenta de lo propio de lo global, sino además, de la situación que viven aquellos habitantes que son expuestos a multiplicidad de estrategias, para pasar de unas formas de vida diferentes a las propias de las historias locales.

\section{Vagos, Ociosos y Malentretenidos²: Algunas pistas para una historia del ocio en las sociedades de la periferia}

Quizás uno de los puntos de mayor importancia en este ejercicio, es la reivindicación de intentar mostrar todas las historias y las miradas. En este sentido y de acuerdo con el momento de reenunciación del ocio, ubicado entre el siglo XVIII y XIX, o segunda modernidad, sólo una parte de la historia se ha hecho visible, la del diseño global Sin embargo, de otro lado, las condiciones propias de las historias locales permanecen ocultas, lo que impide una lectura completa de las condiciones y situaciones que en aquel entonces se desarrollaban, particularmente en América.

La historia del ocio en estas regiones no se corresponde con la de las zonas centrales, por eso se ha planteado que la historia del ocio para noso-

\footnotetext{
2 "El disciplinamiento de la población significó también racionalizar el tiempo de ocio. Los juegos no eran diversión sino “malentretenimiento” y, junto a las pulperías, los lugares de reunión como las canchas, chinganas y la propia calle fueron objeto de vigilancia y control. Juegos y pulperías desviaban de las obligaciones a la gente de trabajo, eran una distracción” (Araya 1999:42).
} 
tros, no es la historia del ocio en Europa. Por el contrario, las condiciones que se presentan en la periferia tienen su propia lógica, que se corresponde eso si, con la intervención del centro bajo el imaginario de la colonialidad del poder, bajo procesos de dominación. Cómo diría Viqueira (1987), no son los campesinos franceses o ingleses, sino los indígenas desarraigados y los africanos importados, expuestos a la esclavitud, la mita ${ }^{3}$ y la encomien$\mathrm{da}^{4}$, bajo la perspectiva de la diferencia colonial, los objetos de un proyecto que de ninguna manera permite una lectura única del fenómeno del ocio.

La asignación de valores, la situación que aun se vivía bajo el dominio de los monarcas españoles, la reconfiguración de una situación de conquista a una colonial, ofrecen por lo menos, algunas pistas para construir una historia que nos permita realmente entender las condiciones bajo las cuales se interviene, no el tiempo libre, sino la vida entera de los habitantes de estos territorios.

De acuerdo con Tabares, Molina y Escobar (2008), no es el interés de este trabajo dar cuenta de las prácticas de aquellos criollos ilustrados, elegidos por el diseño global, como las únicas personas dignas de las prácticas civilizadas del ocio del centro. Interesa si, preguntar por lo que sucedió con aquellos habitantes, caracterizados como seres inferiores, incapaces de lujo y de diversiones racionales (Cadelo 2004:27), cuyas formas de vida era necesario transformar, al servicio del nuevo modelo que intentaba incluirlos en el mundo del trabajo, también subalternizado, de acuerdo con la Colonialidad del poder (Quijano, 2007).

Vale la pena mencionar, la experiencia propia en la búsqueda de información de las prácticas de juego y diversión de clases populares en América, encontrada en los documentos administrativos y judiciales, es decir, en el campo de la prohibición y el castigo. Más que los hombres ociosos, referente de nuestros criollos, se propone, retomando a Araya (1999) la clase de los ociosos, vagabundos y malentretenidos, como referente para indagar las prácticas relacionadas con el ocio de los habitantes de la periferia. Así entonces, el ocio occidental como estrategia civilizadora sobre las formas propias de vida, contra las formas propias de diversión, en el marco del sistema mundo moderno/colonial.

${ }^{3}$ La mita: se constituyó en una modalidad de trabajo no-gratuita pero sí obligatoria para los aborígenes que, además de estar obligados a realizar trabajos forzados en climas malsanos, eran separados de sus familiares, haciendo cada vez más difícil la preservación de su raza. Por el gran número de vidas que consumió esta institución infame, se la considera la más atroz de todas http://www.colombiaaprende.edu.co/html/productos/1685/article139582.html

${ }^{4}$ La encomienda: esta institución consistió en entregar un grupo de indígenas al encomendero, persona encargada de protegerlos y catequizarlos, y éste, a la vez, los utilizaba como mano de obra en sus propias tierras. Esta institución se convirtió en algo cruel que dejo muchos muertos, por eso fue abolida en el siglo XVII http:// www.colombiaaprende.edu.co/html/productos/1685/article-139582.html 


\section{Un momento de transformación en la periferia}

Para Araya (1999:11) el siglo XVIII se corresponde con la transformación de la estructura económica del reino. En el contexto particular de Chille lo plantea como la transición de la ganadería a la producción triguera. Esta situación, según la autora, trajo cambios, en la nueva situación, entre las regiones llamadas por ella más ricas y las más pobres. En este sentido, y en el marco del interés de este apartado, afirma Araya (1999:12): "Los vagabundos serían personajes de transición entre ambas formas de organización económica porque, mientras eran la característica de la predominancia de una, al mismo tiempo eran perseguidos en la otra por constituirse en sujetos "marginales" a la estructura dominante, la que no se identificaba con la movilidad, sino con el arraigo".

En este mismo sentido, plantea Castillo (2000) que "El siglo XVIII representó para España y sus dominios americanos una época de grandes proyectos políticos y administrativos en la que se discutieron los cambios hacia la modernización. La modernización económica y cultural de la población nativa americana a dicho proceso y la forma de hacerlo fueron temas de análisis de los proyectistas españoles de la época”.

Una referencia más, para hacer visible el momento de cambio en el siglo XVIII en América, es Castro-Gómez (2005:16), quien de la mano del concepto de biopolítica, se propone estudiar la Ilustración en la Nueva Granada, mostrando lo que denomina "los esfuerzos del imperio español por implementar una política de control sobre la vida en las colonias hacia mediados del siglo XVIII”. Esfuerzos, que según él, se orientaron al mantenimiento de la hegemonía geopolítica frente a potencias como Francia, Holanda e Inglaterra. En este sentido afirma el autor (2005:16): "la Corona española quiso aprovechar los discursos de la ciencia moderna para ejercer un control racional sobre la población y el territorio”.

Un último apunte lo ofrece Viqueira (1987:9) quien afirma:

De hecho inicie la investigación que dio como fruto este trabajo buscando en el siglo XVIII novohispano un espejo en el cual pudiera mirarse el presente. Intentaba saber como una época y una sociedad había inventado una forma más libre de llevar cotidianamente la vida.

Pero buscando esta liberación de la vida social me tope con algo en sumo grado distinto, con el despotismo ilustrado, ese engendro monstruoso nacido del acoplamiento entre el poder absoluto y el saber.

De esta manera, se evidencia la transformación en los espacios de la periferia, mostrando como, si bien es cierto, los cambios en el mundo repercutieron en estas regiones, no basta con una lectura que desconoce las realidades propias que se viven en una sociedad, donde desde la conquista, bajo el patrón de la colonialidad del poder, que clasificó a los seres huma- 
nos de acuerdo con el criterio de raza y con la asignación de unos valores que definen a cada una de ellas. Esta situación concreta de la periferia es la que se intentará mostrar, ratificando la importancia de una mirada desde los imaginarios de la primera modernidad, pues es sobre ellos que se asientan las reconfiguraciones de las sociedades periféricas en otras fases del proyecto civilizador.

Es pues este momento en el siglo XVIII, el que se propone como punto de las nuevas enunciaciones en la Nueva Granada, y por tanto, referente para el análisis de este fenómeno hasta nuestros días.

\section{Ociosos, vagos y Malentretenidos}

Identificado el siglo VXIII, como un periodo de cambio, lo siguiente es indagar, cómo el nuevo proyecto, bajo los referentes del periodo llamado de la conquista, comprende a los habitantes de estas tierras.

Para Araya (1999:18), en referencia al trabajo, las nuevas transformaciones, identificaron a la población como trabajadores libres, que debían desarrollar ocupaciones lícitas y en relación de dependencia. Sin embargo, esta población libre representaba una amenaza para las capas dominantes, quienes como estrategia, convirtieron a los nuevos libres en plebe, mediante la actualización y relacionamiento de esta población con el antiguo concepto de ociosidad. Es decir, en palabras de Araya (1999:18): "La ociosidad se objetivó en la plebe”.

De esta manera entonces, en la perspectiva del análisis de este trabajo, la ociosidad se convirtió en el referente para identificar a la población y para justificar todas las medidas que en adelante se asumirían en los diferentes ámbitos de la sociedad.

Según Araya (1999:18):

En primer lugar, la ociosidad era un indicador de la población que tenía la obligación de trabajar. En un primer momento los indios fueron calificados de naturaleza ociosa. En el siglo XVIII, todos los hombres libres - mestizos en un sentido amplio- también la poseían. El discurso sobre la ociosidad, por tanto, era una teoría antropológica ya que, si se era catalogado de ocioso, por naturaleza se era capaz de cualquier vicio, pecado, desorden o delito. La plebe era moralmente inferior. Esta inferioridad legitimó las medidas de orden y disciplinamiento sobre ella, las que se asumieron como objetivos de un buen gobierno. La corrección y el castigo pasaron a ser los principales objetivos de esta nueva tarea civilizadora.

En este marco, con el trabajo como eje central de los nuevos procesos de control y disciplinamiento, como referente de utilidad y aprovechamiento de energías y tiempo, la ociosidad, la vagabundería y el 
malentretenimiento, aparecen como un problema social nuevo, sobre el que interviene el modelo dominante para su reconfiguración.

De esta manera, y a partir de este momento, la nueva categoría asignada a la población que no se inserta en el nuevo modelo empieza a ser caracterizada y objeto de discursos y medidas en tal sentido.

En palabras de Araya (1999:19)

El ocioso vagabundo pasó a encarnar todas las conductas consideradas inútiles y perjudiciales para el orden del espacio social. No sólo el que no se encontraba ejerciendo su trabajo era un ocioso sino también el que incurría en acciones que lo desviaban de esta obligación moral y social de trabajar. Era un "vago” el que concurría a las canchas de juego y las pulperías, la diversión y la distracción eran riesgosas para la comunidad del trabajo y sobre todo perjudiciales para los empleadores que veían en estas aficiones posibles fallas de inconstancia.

Así, el siglo XVIII representa para las sociedades de América un momento crucial, por representar una época donde se hace posible leer la otra cara, la colonial, y no sólo aquella tradicional, que busca dar cuenta del avance del modelo global, pasando por alto las condiciones de las personas de las historias locales. Ello marca aspectos importantes que deben ser tenidos en cuenta para mostrar las condiciones en ese momento y lugar y de los condicionamientos para el ocio de la población nativa.

La ociosidad, como un nuevo discurso que se enmarca en las nuevas conformaciones del trabajo en la periferia, donde el ocio no representa precisamente un referente de autonomía y libertad. En la perspectiva de la diferencia colonial, la ociosidad, se asigna como un elemento constitutivo de los habitantes de la periferia, y no de las características propias de la diferencia y que en el marco del diseño global debía ser implementado cambiando usos y costumbres locales.

\section{Afirma Araya (1999:36):}

En el siglo XVIII el discurso de la ociosidad era un discurso sobre el trabajo, la utilidad y el orden que se dirigió principalmente a la población libre avalando las medidas de compulsión al trabajo y también aquellas tendencias al control de las conductas que afectasen el orden laboral. En este siglo cristalizó la noción de ociosidad que señala que es un vicio perder el tiempo, malgastarlo o desperdiciarlo, dejando pasar inútilmente no haciendo nada o no ocupándose en cosa alguna.

En este mismo sentido Araya (1999:36) afirma que el discurso sobre la ociosidad, formó parte, como elemento central, en todo el proceso que emprendieron las clases dominantes, como estrategia disciplinadora 
para afianzar el control sobre las personas, aprovechando su gran utilidad, planteada ya por Castro-Gómez (2005) en relación con el conocimiento de las ideas de orden y civilización planteadas por el racionalismo ilustrado. Y culmina Araya (1999:36): "En el siglo XVIII la expresión “ociosidad y vagabundidad” reunía todas las faltas al trabajo lícito, por tanto a la virtud y a la civilidad".

De esta manera la ociosidad y el vagabundeo hacen referencia a la ausencia de trabajo lícito, entendido como aquel que se daba en sujeción a servicio. Es decir, la persona que se resistía a la falta de dependencia, devenía en vagabundeo.

El marco de la diferencia colonial se hace presente, cuando desde la raza, se asignan unos ciertos valores. Ser civilizado en el siglo XVIII representa ejercer trabajo lícito y en condición de dependencia.

En esta dirección plantea Araya (1999:40): "El discurso sobre la ociosidad en el ámbito de la productividad tiene el cariz de "tacha" (estigma), una especie de indicador de la población que se deseaba fuese compelida al trabajo. Esta tacha o estigma supone una concepción del que la recibe. Los primeros en recibir la tacha de ociosos habían sido los indios”.

Para el siglo XVIII entonces, un nuevo discurso se reconfigura para asignar a la naturaleza de los nativos y mestizos la condición de ociosidad. Dicho de otra manera, los habitantes y los posibles cruces entre estos y otros grupos. Los mestizos asumen como la población que debe asumir el rol de mano de obra. Homogenizados como "gente inferior", por parte de los segmentos dominantes, son asimilados como tendentes a los vicios provenientes de la ociosidad como tacha heredada. Barros Arana, citado por Araya (1999:41), habla de los mestizos como la miserable condición de las clases inferiores. Y afirma además: "El mestizo debía su situación, ser miserable, a los "vicios inherentes a las dos razas de que provenía, a la ignorancia en que estaba sumida y a la miseria creada por la falta de industria” (Araya 1999: 41)

Barros Arana ${ }^{5}$, concibe entonces a los mestizos como seres miserables, que se explica, según él, exclusivamente, por la poca aplicación al trabajo. Afirma en este sentido (Araya 1999:42): "Esta herencia afectaba, sobre todo, la obligación moral, individual y de responsabilidad social que tenía el mestizo ante el resto de la sociedad: trabajar". La tacha de ociosidad, entonces se extendía ahora a un sector social denominado "plebe" que debemos entender como mestizo y peón izado (o peonizable)” (Araya 1999:42).

${ }^{5}$ Diego Barros Arana. Historiador Chileno (1830-1907), cuya obra principal es Historia General de Chile. 
Para Araya (1999:45) esta situación toma visos de teoría antropológica que convertía a los seres humanos catalogados como plebe, en seres inferiores cuyos vicios debían ser corregidos. De esta manera, aparecen planteamientos como el hecho por Luís Manuel de Zañartu, corregidor de Santiago (1762), para quien la ociosidad de la plebe, fue un asunto de “conversión”, una especie de nueva empresa de conquista y civilización.

Así, se hace visible el trasfondo de estas configuraciones, que se asientan sobre una máquina que opera en la asignación de valores a los habitantes de la periferia. Idólatras, salvajes, incivilizados y ahora vagos, ociosos y malentretenidos, son aportaciones de una misma matriz. Una referencia textual a Araya, permite hacer evidente el real contexto de las circunstancia en el siglo XVIII: "El disciplinamiento de la población significó también racionalizar el tiempo de ocio. Los juegos no eran diversión sino malentretenimiento y, junto a las pulperías, los lugares de reunión como canchas, chinganas y la propia calle fueron objeto de vigilancia y control. Juegos y pulperías desviaban de las obligaciones a la gente de trabajo, eran una “distracción” (Araya 1999:47).

Una última referencia a Araya, permite dejar clara la operación hecha por las capas dominantes para no sólo utilizar estrategias de control, sino además, de hacerlo desde una operación que se repite una y otra vez hasta la actualidad, la diferencia colonial.

A mediados del siglo XVIII, la plebe era "peligrosa” tanto por su número como por su diversidad. Esta percepción llevó a que las autoridades hiciesen del disciplinamiento social una tarea prioritaria, el miedo a la población numerosa, desconocida y diversa desconcertó a los grupos dominantes. Ya no se trataba simplemente de indios y españoles, ni siquiera de estos y mestizos, sino de toda clase de mezclas. Las distinciones por el color de la piel tampoco eran útiles cuando éste se hacía más uniforme. A fines del siglo XVIII, por ejemplo, para reafirmar la estratificación social que el color de la piel ya no aseguraba, se recurrió a la vigilancia en el vestir correcto de cada cual de acuerdo a "su estado, sexo y calidad”. Esta realidad distinta llevó a repensar sobre el problema de la dominación y cómo enfrentarlo, quiénes dominaban y quienes eran subordinados. Se resolvió calificando al otro, objeto de dominación, como inferior y débil. (Araya 1999:48).

De esta manera, y dejando claro que la finalidad no es hacer una investigación histórica a fondo, se hace visible cómo las operaciones de distinción a partir de la diferencia colonial, condicionan la vida de las personas que habitaban las sociedades de América Latina. Esto permite comprender la situación que se presenta, como traducción de un fenómeno global, hecha en principio por colonizadores y después por las clases nativas que aparecían como dominantes, para mantener sus privilegios sobre las mayorías. 


\section{Conclusión}

El campo de los estudios de ocio, ha sido abordado tradicionalmente como un diseño global, cuyo análisis se ha centrado en los grados de instauración en los diferentes espacios del mundo. Los espacios de la periferia, como objetos de intervención y muy pocas veces como sujetos protagónicos, en la mayoría de las veces, han asumido los marcos referenciales impuestos desde el centro, como verdades irrefutables. Entender que el campo del ocio es configurado por múltiples expresiones, condicionadas por aspectos sociales, culturales, políticos, económicos, etc., permite asumir una postura crítica, que reivindica la restitución del papel de las sociedades de la periferia en la construcción de marcos referenciales propios, en donde quepa la complejidad y diversidad se sus realidades. Hacerlo, permitiría hacer visible la compleja relación de tensión que existe entre diferentes perspectivas y expresiones, y el papel que debe ser asumido por los académicos de la periferia, buscando posibles salidas a los problemas más acuciantes de nuestros países. El ocio como ámbito por excelencia de la diversidad y la diferencia, debe ser potenciado desde lo local, no para negar todo lo demás -más propio de los diseños globales-, sino para construir referentes amplios que permitan la coexistencia de todas las perspectivas, pero esta vez en igualdad de condiciones. Entender la particularidad de nuestro espacio, permitirá avanzar en nuevos abordajes de este fenómeno, tan descuidado y poco tenido en cuenta a la hora de dar cuenta del bienestar humano en nuestros países. 


\section{Bibliografía}

Araya, A. (1999), Ociosos, vagabundos y malentretenidos en Chile colonial. Centro de Investigaciones Barros Arana/Dirección de Archivos, Bibliotecas y Museos de Chile. Santiago.

Cadelo, S. (2004), “Hábito e ideología criolla en el Semanario del Nuevo Reino de Granada”. En Castro-Gómez, S. (editor) (2004) Pensar el siglo XIX. Cultura. biopolítica y modernidad en Colombia. Pittsburg: Biblioteca de América. Instituto Internacional de Literatura Iberoamericana. Universidad de Pittsburg

Castillo, J. (2000), Ocioso, pobre e incivilizado: algunos conceptos e ideas acerca del Maya Yukateko a fines del siglo XVIII. Mesoamérica. Volumen 21, Nro. 39, 239-254

Castro-Gómez, S. (2005), La Hybris del punto cero. Ciencia, raza e ilustración en la nueva Granada (1750-1816). Editorial Pontificia Universidad Javeriana. Bogotá.

Castro-Gómez, S. y Restrepo, E. (Editores) (2008), Genealogías de la colombianidad. Editorial Pontificia Universidad Javeriana, Instituto de Estudios Sociales y culturales Pensar, Bogota.

Díaz, E. (2008), “Raza, pueblo y pobres: las tres estrategias biopolíticas del siglo XX en Colombia (1873-1962)”, en Castro-Gómez, S. y Díaz, E. (editores) Genealogías de la colombianidad, Editorial Pontificia Universidad Javeriana, Instituto de Estudios Sociales y Culturales Pensar, Bogotá.

Gomes, C. (2003), Significados de RecreaÇao e lazer no Brasil. Reflexoes a partir da análise de experiências institucionais (1926-1964), UFMG, Belo Horizonte.

Idem (2007), “O ocio como objeto de estudos: notas introdutórias sobre conceitos e ocurrencia historica em nossa sociedade”, en Revista Cuadernos de ocio y sociedad $N^{o}$ s 1 y 2, Medellín-Colombia.

Gómez, H. (2006), Juegos recreativos tradicionales de la calle. Una herramienta pedagógica, L. Vieco e Hijas Ltda., Medellín-Colombia.

Kelly, J. (2000), “Asuntos del milenio. Una perspectiva global”. En Cuenca, M. (ed.) Ocio y desarrollo humano. Propuestas para el $6^{\circ}$ Congreso Mundial de Ocio, Universidad de Deusto, Bilbao.

López, A. (1992), Juegos, fiestas y diversiones en la América española, MAPFRE, Madrid. 
Mignolo, W. (2003), Historias locales/diseños globales. Colonialidad, conocimientos subalternos y pensamiento fronterizo. Ediciones Akal, S.A., Madrid.

Purcell, F. (2000), Diversiones y juegos populares: formas de sociabilidad y crítica social, Colchagua, 1850-1880, Dirección de Bibliotecas, Archivos y Museos, LOM Ediciones; Centro de Investigaciones Diego Barros Arana, Santiago de Chile.

Quijano, A. (2000), Colonialidad del poder, eurocentrismo y América Latina en Lander, E. (Compilador) La colonialidad del saber: eurocentrismo y ciencias sociales. Perspectivas latinoamericanas, CLACSO, Buenos Aires.

Idem (2007), Colonialidad del poder y clasificación social en CastroGómez, S, y Groesfel, R. (compiladores) El giro decolonial. reflexiones para una diversidad epistémica más allá del capitalismo global, Siglo del Hombre Editores; Universidad Central, Instituto de Estudios Sociales Contemporáneos y Pontificia Universidad Javeriana, Instituto Pensar, Bogotá.

Tabares, F., Escobar. A., Molina, V., "Notas para un juego-deporte insubordinado o del deporte desde la mirada de la modernidad/colonialidad”. Recorde: Revista de História de Esporte. Diponible en http:// www.sport.ifcs.ufrj.br/recorde/pdf/recordeV1N2_2008_16.pdf. Consultado el 15/06/2009

Tabares, F. y Molina, V. (2009), “Una mirada al ocio en las sociedades de la periferia teniendo como referente el paradigma de la modernidad/ colonialidad”. Espacio Abierto: Cuaderno Venezolano de Sociología Vol. 18, $N^{o} 1$, Maracaibo-Venezuela.

Viqueira, J. (1995), ¿Relajados o reprimidos?: diversiones públicas y vida social en la ciudad de México durante el siglo de las luces, Fondo de Cultura Económica, México D.F. 